\title{
CERÁMICAS ISLÁMICAS DEL CASTELLAR DE MECA
}

Por

ISABEL LÓPEZ GARCÍA

Durante los años 1982 y 1983 , de acuerdo con el convenio de colaboración entre el INEM, el Ministerio de Cultura y el Servicio de Investigación Prehistórica de la Excma. Diputación Provincial de Valencia, se han realizado excavaciones centradas principalmente en la limpieza del camino ibérico, en la muralla y en localizar las puertas de acceso al poblado, ocupándome del estudio de los materiales medievales.

El Castellar de Meca se encuentra situado en el término municipal de Ayora, al suroeste de la población, ya en el límite de las provincias de Valencia y Albacete.

Es un espolón rocoso en las estribaciones septentrionales de la Sierra del Mugrón, con una cota máxima de 1.058 metros sobre el nivel del mar, resultando de una altura superior a los 200 metros sobre la llanura circundante. Forma una amplia meseta de cerca de un kilómetro de longitud por 350 metros de ancho en sus ejes mayores, rodeada por abruptos escarpes que impiden el acceso por todos sus lados excepto por el norte, donde se localiza un gran lienzo de muralla ibérica.

En el poblado se pueden distinguir tres grandes áreas, perfectamente diferenciadas en razón de las peculiaridades constructivas de cada una de ellas.

a) Zona oriental, donde se localizan el camino y construcciones de época ibérica excavados en la roca, así como aljibes que no se limitan a esta zona, sino que en gran número se extienden por toda la meseta.

b) Zona central, en la cual se aprecian monticulos de piedras correspondientes a grandes consstrucciones y donde se puede ver el trazado de las calles de acuerdo a un cuidado plan urbanístico de época medieval.

c) Zona occidental, constituida por un pequeño recinto probablemente de época imperial romana.

El poblado medieval se extendería por la zona oriental, reutilizando las construcciones ibéricas, donde en superficie se pueden encontrar fragmentos de cerámica decorada en verde y mangeneso del estilo de Madinat al-Zahra' y de cuerda seca total, y por la parte central asentado sobre el poblado ibérico. 
Debido a la ausencia de otras estribaciones montañosas que lo protejan del fuerte viento y a las inclemencias climatológicas propias de la zona, la meseta se encuentra considerablemente erosionada, quedando al descubierto los muros de las edificaciones y aflorando a la superficie en ocasiones la roca. Ante esta situación resulta difícil localizar puntos con suficiente potencia de tierra que haya protegido el yacimiento, apareciendo gran cantidad de cerámica muy rodada por toda la superficie.

Han aparecido en la puerta situada al Este fragmentos de un ataifor con decoración de cuerda seca total y de olla acanalada, de cuello exvasado, pasta y superficie exterior gris alisada con un objeto duro, produciendo un brusco desplazamiento del desgrasante (figuras 1.1 y 1.2 ).

En la ladera de la cara norte, sobre el tramo de camino situado ya fuera del poblado, se pudo comprobar la existencia de una puerta de acceso de época medieval asentada sobre una superficie de piedras colocadas irregularmente que inutilizaban el camino ibérico. A partir de esta puerta se ha podido constatar la existencia de habitaciones de época medieval, de planta rectangular, construidas con muros de piedra suelta y asentadas transversalmente sobre el camino, que desgraciadamente resultaron cortadas por la mitad durante la limpieza de éste, debido a la mala construcción de los muros, que hace difícil su identificación.

Hasta el momento se han detectado tres de estas habitaciones, excavándose la que denominamos Departamento 3 , donde se aprecia un fuerte nivel de incendio causante de su destrucción, sobre el cual apareció gran cantidad de material, destacando un alto porcentaje de ollas. Por sus características pueden establecerse varios grupos:

1) Ollas globulares sin asas, de cuello exvasado, pasta y superficie exterior gris, acanaladuras muy poco pronunciadas y con una altura media de 13 centímetros (figuras 1.3 y 1.4 ).

2) Un segundo grupo formado por cinco ollas de forma piriforme, con o sin asas, de pasta y superficies de textura similar a las del grupo primero, o bien de pasta mal amalgamada con desgrasante grueso $y$ abundante y superficie marrón, paredes gruesas de espesores variables, asas de inserción inferior aplicadas por presión con el dedo pulgar y alturas que oscilan de 12,5 a 24 centimetros (figuras $2.1,2.2,3.1,3.2,3.3$ ).

3) Por último, una olla incompleta sin asas, de pasta y superficies beiges $\checkmark$ acanaladuras más pronunciadas que las del primer grupo (figura 3.4).

El resto del material asociado con estas ollas lo forma:

- Un jarrito o jarrita de pasta rojiza mal amalgamada y superficie rojiza alisada. Altura, 11 centímetros; diámetro apertura, 12 centímetros; espesor variable, 0,35 a 1,3 centímetros (figura 3.5 ).

- Botella incompleta de pasta y superficies marrones. Altura conservada, 11,7 centímetros; diámetro apertura, 4,5 centímetros; espesor variable, 0,4 a 0,9 centímetros (figura 4.1 ). 
- Cantimplora de pasta y superficies rojizas, desgrasante abundante, base plana, cuerpo cónico, asas de inserción extendida. Altura, 14,4 centímetros; diámetro base, 10,5 centímetros; diámetro máximo, 14,9 centímetros; diámetro apertura, 3,6 centímetros; espesor 0,5 centímetros (figura 4.3).

- Candil de pico con cazoleta bitroncocónica de diámetro máximo muy acusado, pasta y superficies amarillentas, resalte en la unión de la cazoleta con el gollete $y$ dos líneas incisas paralelas en su diámetro máximo. Altura, 8,2 centímetros; diámetro máximo, 9,5 centímetros; espesor, 0,4 a 0,7 centímetros (figura 4.2).

- Forma abierta de base plana, paredes bitroncocónicas, borde de sección triangular. Altura, 3,5 centímetros; diámetro base, 14 centímetros; diámetro apertura, 17 centímetros; espesor, 0,4 a 0,8 centímetros (figura 4.5 ).

Posiblemente pertenecientes también a esta habitación sean las piezas representadas en las figuras 4.4 y 4.6 , halladas durante la limpieza del camino. La olla es de características similares a las consideradas en el grupo primero, con una mayor concavidad en su base.

En resumen, se trata de conjuntos cerrados, cuyo interés radica en estar sellados por un nivel de incendio. Es un material de aspecto primitivo, con un alto porcentaje de ollas, modelado a torneta, carente en muchos casos de simetría y de tratamiento poco cuidado en sus superficies. Esto, unido a la total ausencia de cerámica vidriada asociada a ellos, hace pensar que se trate de un conjunto anterior a la segunda mitad del siglo $X$, por más que el poblado tuvo una continuidad, tal como parecen probar los fragmentos de cerámica decorada en verde y manganeso del estilo de Madinat al-Zahra' y de cuerda seca total. 


$$
\frac{1}{232}
$$




$$
\sum_{3}
$$




$$
\begin{array}{ll}
-2 & 1 \\
2 & 2 \\
l & 2
\end{array}
$$



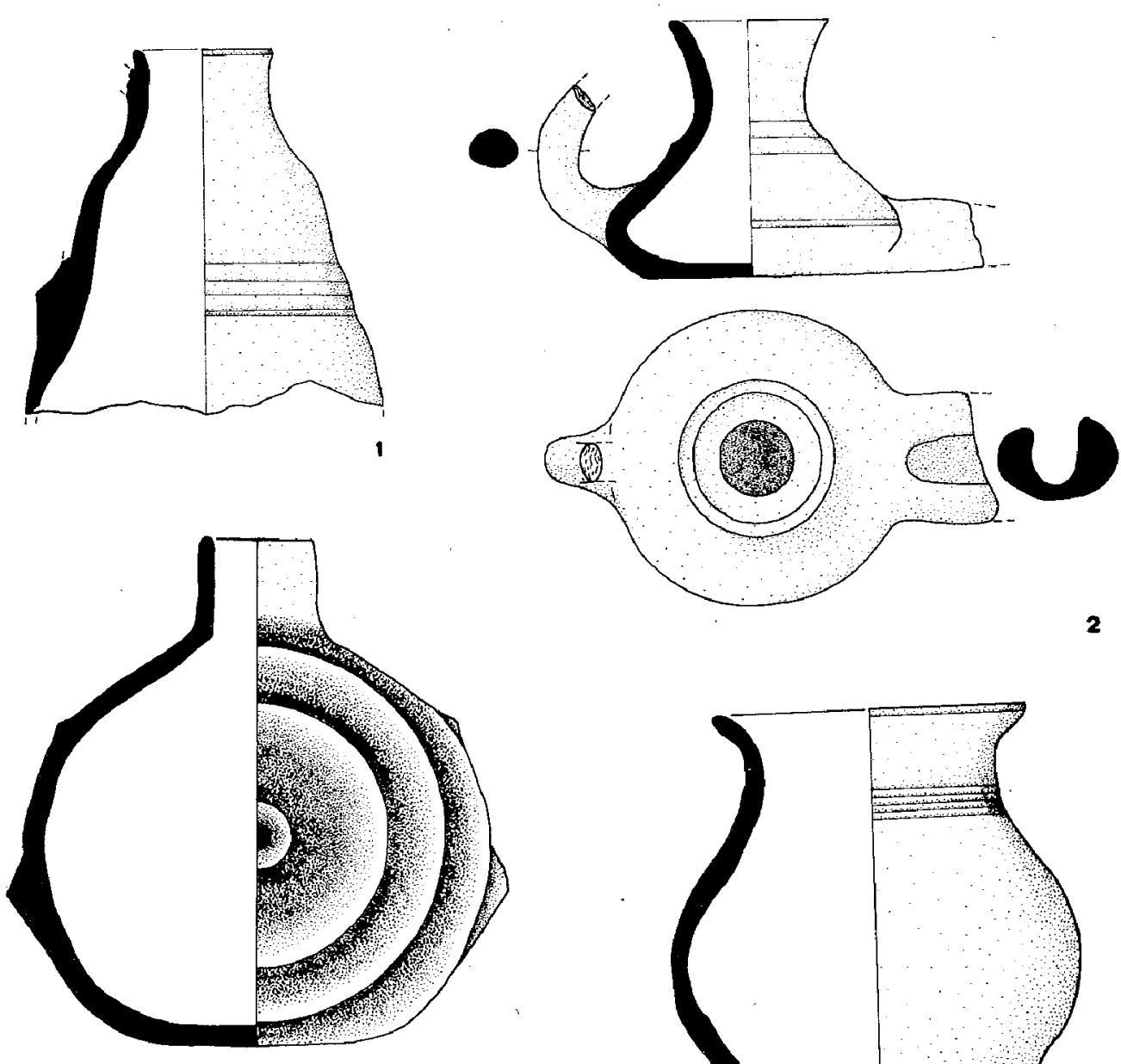

3

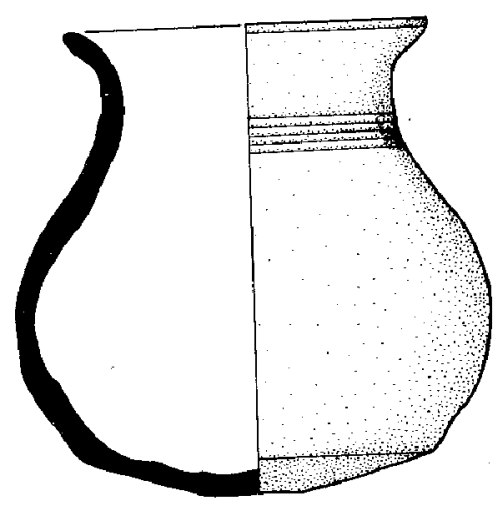

4
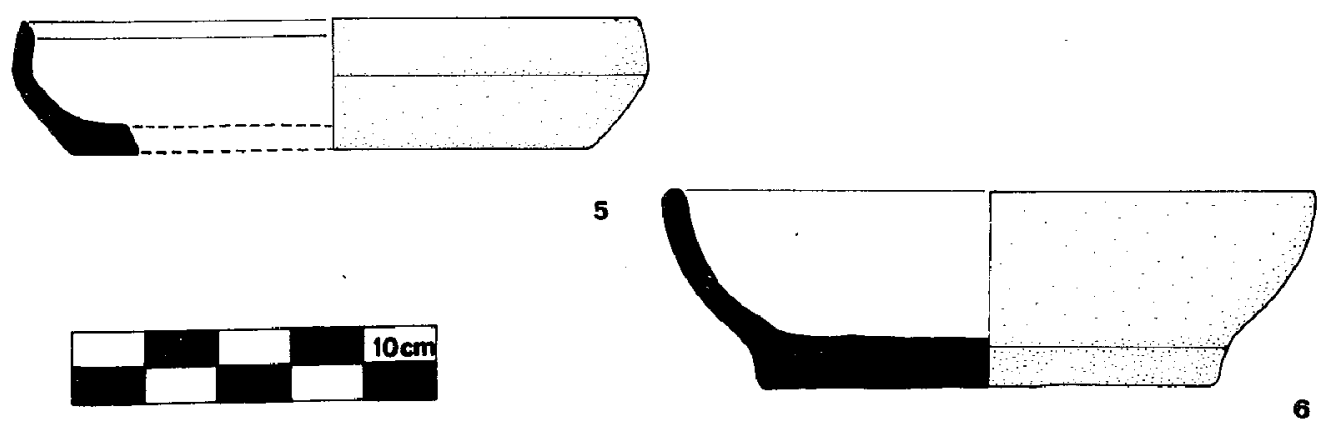